
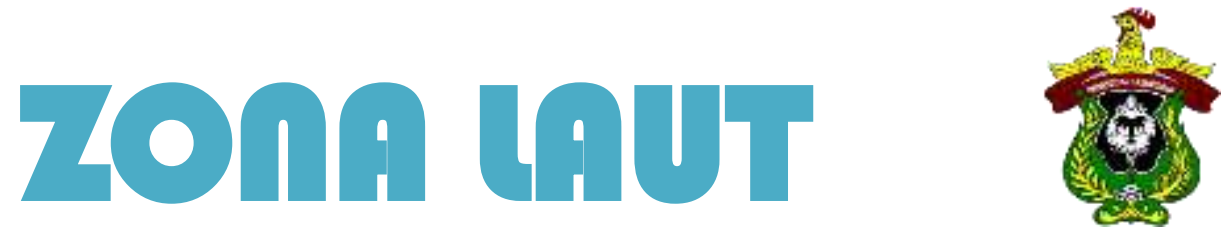

JURNAL INOVASI SAINS DAN TEKNOLOGI KELAUTAN

\title{
PERANCANGAN BANGUNAN KAPAL GENERAL CARGO 17000 DWT UNTUK RUTE PELAYARAN JAKARTA - SEMARANG
}

\author{
*Sulaiman Ali, Habibi Palippui dan Rahmahdani Japri \\ Program Studi Teknik Mesin Fakultas Teknik Universitas Teuku Umar, Aceh \\ *sulaimanali@gmail.com
}

\begin{abstract}
Abstrak
Kapal general cargo adalah kapal yang mengangkut bermacam-macam muatan berupa barang. Barang yang diangkut biasanya merupakan barang yang sudah dikemas. Kapal general cargo dilengkapi dengan crane pengangkut barang untuk memudahkan bongkar-muat muatan. Pada perancangan ini direncanakan desain lambung kapal. Ukuran utama kapal didapatkan dengan menggunakan metode pembanding regresi yang didasarkan pada data 2 kapal pembanding yang di dapat dari korea register of shipping (KRS). Dari ukuran utama yang didapat kemudian dilakukan pembuatan rencana garis dan analisa hidrostatik yang sesuai dengan standar IMO. Dari hasil perencanaan didapat untuk kapal berkapasitas 17000 DWT didapat dimensi kapal dengan length over all (LOA) 153,45 m, length between prependiculars (LBP) 144,24 m, Length on load waterline (LWL) 147,85 m, lebar (B) 25,27 m, tinggi (H) 13,5 m, sarat (T) 9,52 m, kecepatan (V) 14,75 Knot, coeffisien block $(\mathrm{Cb})$ 0,7, coeffisien midship $(\mathrm{Cm})$ 0,79, coeffisien waterline (Cw) 0,81, coeffisien prismatic horizontal (Cph) 0,91, coeffisien prismatic vertical (Cpv) 0,89, volume $25520,5 \mathrm{~m}^{3}$. Metode kapal pembanding ini memudahkan perancang kapal dengan hasil yang akurat.
\end{abstract}

Kata Kunci: General Cargo,Rencana Garis, Hidrostatic.

\begin{abstract}
Abstrct
General cargo ship is a ship that carries various kinds of cargo in the form of goods. Goods that are transported are usually packaged goods. General cargo ships are equipped with cargo cranes to make loading and unloading easier. In this design the hull design is planned. The main size of the ship was obtained using a regression comparison method based on data from 2 comparison vessels obtained from the Korea Register of Shipping (KRS). From the main dimensions obtained, a line plan and hydrostatic analysis is carried out according to the IMO standard. From the planning results obtained for ships with a capacity of 17000 DWT obtained ship dimensions with length over all (LOA) $153.45 \mathrm{~m}$, length between prependiculars (LBP) $144.24 \mathrm{~m}$, Length on load waterline (LWL) $147.85 \mathrm{~m}$, width (B) 25.27 $m$, height $(H) 13.5 \mathrm{~m}$, loaded $(T) 9.52 \mathrm{~m}$, speed $(\mathrm{Vs}) 14.75$ knots, block coefficient $(\mathrm{Cb}) 0.7$, midship coefficient $(\mathrm{Cm})$ 0.79 , waterline coefficient ( $C w$ ) 0.81 , horizontal prismatic coefficient (Cph) 0.91 , vertical prismatic coefficient (Cpv) 0.89 , volume $25520.5 \mathrm{~m} 3$. This comparison ship method makes it easy for ship designers with accurate results.
\end{abstract}

Keywords: General Cargo, Lines Plan, Hidrostatic.

\section{PENDAHULAN}

Sebagai negara maritim, sangatlah perlu peningkatan armada laut baik untuk keperluan eksplorasi kelautan maupun sebagai sarana penunjang ekonomi di wilayah perairan Indonesia. Peran pemerintah dalam memprioritaskan pembangunan sektor kelautan sangat dibutuhkan agar mampu bersaing dengan negara lain . Bukan hanya bidang pertahanan tetapi juga bidang perniagaan. Asosiasi Perusahaan Pelayaran Indonesia (Indonesian National Shipowners Association/INSA) memproyeksikan, dalam periode 2012-2017 Indonesia membutuhkan sekitar 4.000 unit kapal baru. Penambahan itu sendiri untuk meluncurkan layanan baru, meningkatkan kapasitas, mengganti kapal lama [1][2], dan melancarkan arus distribusi barang dari dan keluar Indonesia dengan jenis kapal beserta teknologinya yang baru[6]. Berdasarkan asumsi bahwa pada tahun 2005 ada sebanyak 6.041 unit dan kemudian meningkat sebanyak 3.904 (65,4\%) menjadi 9.945 di 
tahun 2010. maka dibutuhkan 780 kapal tiap tahunnya atau sebanyak 4.000 kapal dari 2012-2017 dengan asumsi ekonomi tumbuh stabil di 6,5\% per tahun dan volume kargo naik 10-15\% per tahun [3], [4][5].

\section{METODE PENELITIAN}

Dalam pengambilan data, Metode yang digunakan adalah melakukan analisa dan pengolahan data maka akan di dapatkan model kapal, hidrostatik kapal dan stabilitas kapal. Semua hasil pengolahan data berupa gambar, grafik, serta perhitungan yang diperoleh hasil dari proses tersebut, kemudian dilakukan pengelompokan agar mudah dalam penyusunan laporan.

\section{HASIL DAN PEMBAHASAN}

\subsection{Penentuan Ukuran Utama Kapal}

Dalam penentuan ukuran utama kapal ini, metode yang digunakan adalah metode perbandingan (comparison method) dengan menggunakan metode regresi linier (linier regression method). Dan didapatkan ukuran utama kapal sebagai berikut :

Tabel 1. Dimensi utama kapal

\begin{tabular}{lll}
\hline Nama Kapal & MATARAM & \\
\hline DWT & 17000 & $\mathrm{~m}$ \\
LOA & 153.45 & $\mathrm{~m}$ \\
LBP & 144.2 & $\mathrm{~m}$ \\
$\mathrm{H}$ & 13.5 & $\mathrm{~m}$ \\
$\mathrm{~T}$ & 9.52 & $\mathrm{~m}$ \\
$\mathrm{~B}$ & 25.27 & $\mathrm{~m}$ \\
V. & 14.75 & $\mathrm{knot}$ \\
Volume & 25520,5 & $\mathrm{~m}^{3}$ \\
\hline
\end{tabular}

Tahap awal yang harus dilakukan adalah membuat rencana garis dalam tugas akhir ini, pembuatan lines plan. Terlebih dahulu mengetahui lebih dahulu ukuran besar kecilnya kapal, seperti panjang, lebar maupun tinggi badan kapal. Berikut adalah perhitungan-perhitungan yang mempengaruhi bentuk kapal.
a. Menentukan nilai Lwl (Length of water line)
b. Menentukan nilai $\mathrm{Cb}$ (Coefisien block)
c. Menentukan nilai $\mathrm{Cm}$ (Coefisien midship)
d. Menentukan nilai $\mathrm{Cp}$ (Coefisien prismatic)
e. Koefisien Prismatik Memanjang (Cp)
f. Koefisien Prismatik Tegak (Cpv)
g. Menentukan nilai Cwl(Coefisien water line)
h. Menentukan nilai V (Volume kapal)
i. Menentukan nilai Am (Luas midship)
j. Menentukan jumlah station dari AP s/d FP (main part)
k. Perhitungan Main Part
1. Perhitungan Can Part
m. Menentukan garis geladak tepi(Sheer)
n. Menentukan garis geladag tengah (Chamber)
o. Menentukan garis kubu-kubu (Bulwark)
p. Menentukan geladak kimbul (Poop Deck)
q. Menentukan geladak akil (Forecastle Deck) 


\subsection{SAC ( Kurva Area Bagian)}

Kurva yang menggambarkan luas gading untuk setiap bagian. Dari kurva SAC ini terlihat banyaknya gading semu yang berada pada tubuh bagian tengah yang sejajar dan berada di bagian tengah yang berbentuk garis lurus. Fungsi dari kurva SAC ini tidak hanya untuk mengetahui bentuk dan luas tiap gading tetapi juga untuk menghitung volume desain, dengan menjumlahkan luas penampang pada kurva SAC. Untuk mendeskripsikan setiap bagian kita membutuhkan lebar garis air konstruksi, tinggi $(\mathrm{H})$, untuk tinggi konstan kapal normal di seluruh kapal dan lebar lokal di dek atas. Dari perhitungan menggunakan rumus perkiraan, diperoleh hasil koreksi SAC yang ditampilkan pada tabel dan gambar grafik berikut.

Tabel 1. Ringkasan Kurva Area Setional

\begin{tabular}{llllll}
\hline Sectionn & Area Bagian & Simpson & Hasil I & Momen & Hasil II \\
\hline & II & FS & II * III = IV & V. & IV * V = VI \\
$\mathrm{a}$ & 0 & 0.25 & 0,000 & $-10,50$ & 0,000 \\
$\mathrm{~b}$ & 2.000 & 1.00 & 2.000 & $-10,25$ & $-20,500$ \\
0 & 17,6 & 1.25 & 22,000 & -10.00 & $-220,000$ \\
1 & 58,8 & 4 & 235,200 & -9.00 & $-2116,800$ \\
2 & 102,7 & 2 & 205,400 & -8.00 & $-1643,200$ \\
3 & 141,2 & 4 & 564,800 & -7.00 & $-3953,600$ \\
4 & 175 & 2 & 350,000 & -6.00 & $-4140,000$ \\
5 & 207 & 4 & 828,000 & -5.00 & $-1840,000$ \\
6 & 230 & 2 & 460,000 & -4.00 & $-2850,477$ \\
7 & 237,5397 & 4 & 950,159 & -3.00 & $-950,159$ \\
8 & 237,5397 & 2 & 475,079 & -2.00 & $-950,159$ \\
9 & 237,5397 & 4 & 950,159 & -1.00 & 0,000 \\
10 & 237,5397 & 2 & 475,079 & 0,00 & 950,159 \\
11 & 237,5397 & 4 & 950,159 & 1.00 & 950,159 \\
12 & 237,5397 & 2 & 475,079 & 2.00 & 2850,477 \\
13 & 237,5397 & 4 & 950,159 & 3.00 & 1853,400 \\
14 & 231,7 & 2 & 463,400 & 4.00 & 4324,000 \\
15 & 216,2 & 4 & 864,800 & 5.00 & 2286,000 \\
16 & 190,5 & 2 & 381,000 & 6.00 & 4183,200 \\
17 & 149,4 & 4 & 597,600 & 7.00 & 1643,200 \\
18 & 102,7 & 2 & 205,400 & 8.00 & 0,000 \\
19 & 53,4 & 4 & 213,600 & 9.00 & 1922,400 \\
20 & 0,000 & 1 & 0,000 & 10.00 & 0,000 \\
& & $\Sigma 1=$ & 10619,074 & $\Sigma 2=$ & 178,300 \\
\hline
\end{tabular}

Persamaan volume SAC:

$$
\frac{1}{3} \times \frac{L B P}{20} \times \Sigma 1
$$

maka diperoleh: $25528,254 \mathrm{~m}^{3}$

Persamaan LCB:

$$
\frac{L B P}{20} \times \frac{\Sigma 2}{\Sigma 1}
$$

maka diperoleh: 0,121

Persamaan Volume Desain:

$$
L W L \times B \times T \times C b
$$

maka diperoleh: 25520,548 $\mathrm{m}^{3}$ copyright is published under Lisensi Creative Commons Atribusi 4.0 Internasional. 
Persamaan Volume Koreksi:

$$
\frac{S A C \text { volume }- \text { Design Volume }}{S A C \text { volume }} \times 100 \%
$$

maka diperoleh: $0.000 \%$

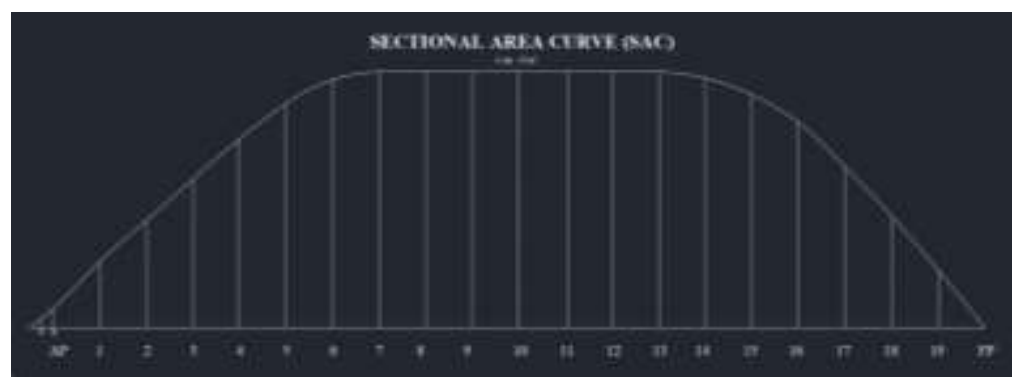

Gambar 1. SAC

\subsection{Rencana Garis}

Setelah menghitung nilai-nilai yang mempengaruhi bentuk kapal, maka langkah selanjutnya adalah pembuatan model menggunakan Software AutoCAd 2017. Berikut ini adalah original model yang dibuat dengan menggunakan Software AutoCAd 2017.

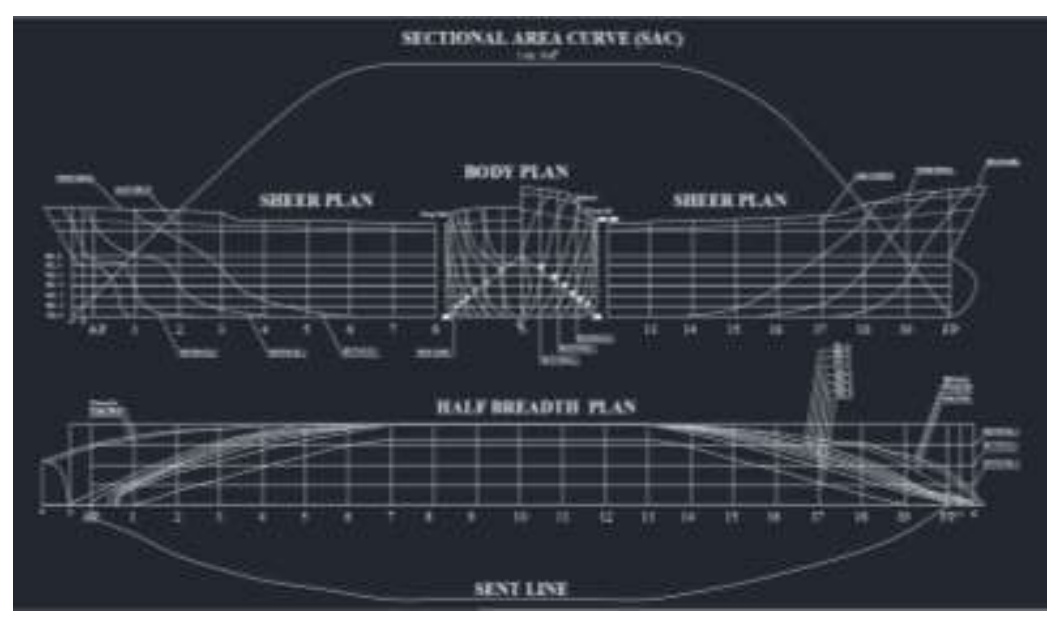

Gambar 2. Lines Plan

\subsection{Kurva Hidrostatik}

Kurva Hidrostatik Lengkungan Hidrostatik merupakan sebuah gambar kurva yang menggambarkan sifatsifat badan kapal yang tercelup dalam air atau untuk mengetahui sifat-sifat carene. lengkungan hidrostatik digambarkan sampai sarat penuh dan tidak dalam kondisi trim (even keel). Gambar hidrostatik mempunyai lengkungan yang masing-masing menggambarkan sifat-sifat atau karakteristik badan kapal yang terbenam dalam air. Berikut gambar dari kurva hidrostatik berdasarkan analisis mengunakan software AutoCad 2017. 


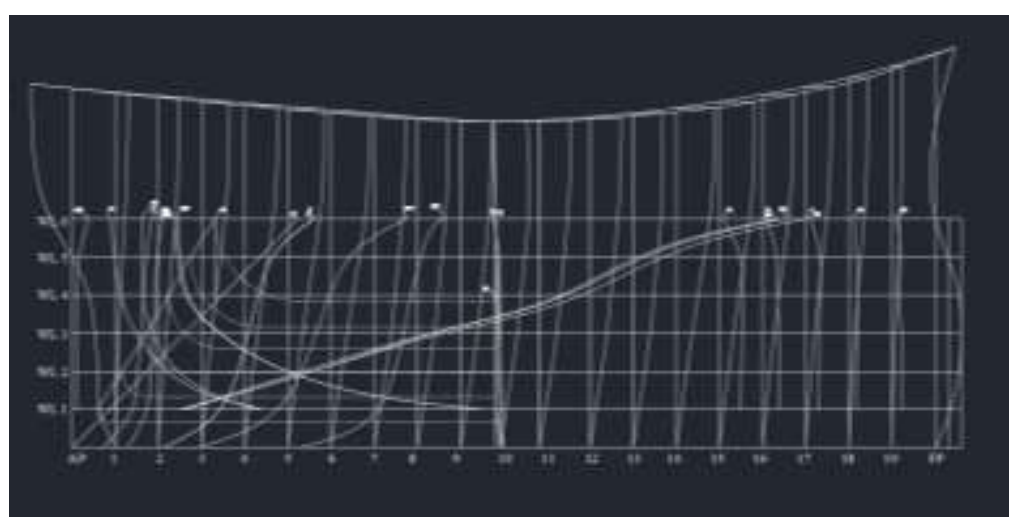

Gambar 1. Hidrostatic and Bounjean Curve

\section{KESIMPULAN}

Berdasarkan hasil perancangan yang dilakukan dapat di tarik beberapa kesimpulan sebagi berikut:

1. Menggunakan metode perancangan regresi didapatkan ukuran kapal LOA $=153,45 \mathrm{~m}, \mathrm{LBP}=144,24 \mathrm{~m}$, $\mathrm{LWL}=147,85 \mathrm{~m}, \mathrm{~B}=25,27 \mathrm{~m}, \mathrm{H}=13,5 \mathrm{~m}, \mathrm{~T}=9,52 \mathrm{~m}, \mathrm{~V}=14,75 \mathrm{Knot}, \mathrm{Cb}=0,7, \mathrm{Cm}=0,79, \mathrm{Cw}=$ $0,81, \mathrm{Cph}=0,91, \mathrm{Cpv}=0,89$, volume $=25520,5 \mathrm{~m}^{3}$.

2. Pada gambar lines plan di dapat bahwa bentuk badan kapal telah sesuai dengan fungsinya.

3. Dari perhitungan telah di dapat berat DWT 17000 ton

4. Dari rencana garis air ini selanjutnya digunakan dalam perhitungan dan penggambaran bonjean dan hydrostatic curve. Bonjean dan kurva hidrostatika digunakan untuk mengetahui sifat dan karakteristik kapal di bawah air pada setiap kondisi sarat.

\section{DAFTAR PUSTAKA}

[1] Habibi, "Kegagalan Sistem Keselamatan Transportasi Laut di Indonesia (Failure of the Marine Transportation Safety System in Indonesia)," J. Apl. Pelayaran dan Kepelabuhanan, vol. 8, no. 2, pp. 95-106, 2018.

[2] S. Hidayat dan H. Palippui, "Analisis Dampak Penerapan Kebijakan Bonded Warehouse (Gudang Berikat) Terhadap Biaya Logistik Di Pelabuhan", zonalaut, vol. 1, no. 3, hlm. 84-91, Nov 2020.

[3] Niagara, gigih. 2013. Perancangan kapal kargo 1500 DWT rute pelayaran jakarta-surabaya. Semarang: teknik perkapalan Universitas diponegoro. Vol 10, No.2.1

[4] Rawson K.J, and E.C Tupper. 2001. Basic ship theory. Oxford. Butterworth heinemann. Vol.1, no.5.

[5] Rules Biro Klasifikasi Indonesia 2006.

[6] Schneekluth, H., and V.Bertram. 1998. Ship design for efficiency. Oxford. Butterworth heinemann. No.2. 